\title{
La perícopa de la mujer adúltera en el Evangelio de Juan y en las Comunidades Judeocristianas
}

\author{
The Pericope of The Adulterous Woman in The Gospel \\ of John and in Judeo-Christian Communities
}

\begin{abstract}
Resumen
En este artículo se parte de los aportes de la memoria colectiva al estudio del texto del Nuevo Testamento (NT) y específicamente con el caso de la perícopa de la mujer sorprendida en adulterio (PMA), la cual va a incorporada tardíamente al evangelio de Juan (EJ), en el capítulo 8, según se plantea desde la Crítica Textual. El texto recobra una nueva importancia a la luz de los aportes de la memoria como parte de la tradición de comunidades judeocristianas en el inicio de cristianismo. Lo anterior implicará su ubicación en el contexto de los primeros siglos del cristianismo y no sólo en el contexto propio de la tradición jóanica, en donde se ubica como parte de la confrontación de Jesús con sus antagonistas judíos.
\end{abstract}

Palabras claves: Memoria colectiva, Movimiento judeocristiano, Evangelio de Juan, Jesús y la mujer adúltera.

\begin{abstract}
This article takes up some of the contributions of memory to the study of the text of the New Testament (NT) and specifically to that of the pericope of the woman caught in adultery, which will be added belatedly of the Gospel of John (JG), in chapter 8 , as it arises the Textual Criticism. The text regains a new importance considering the contributions of memory as part of the tradition of the Judeo-Christian communities. This will imply giving a seeing in the context of the first centuries of Christianity and not only in the context of the Joanic Tradition, where it is in the context of Jesus' confrontation with her Jews antagonists.
\end{abstract}

Key words: Collective memory, Judeo-Christian communities, Gospel of John, Jesus and the woman caught in adultery.

\footnotetext{
${ }^{1}$ Roberto Caicedo Narváez, licenciado en Ciencias Bíblicas, Magíster en Teología y Doctorado en Ciencias Sociales. Profesor y director de la Maestría en Teología de la Fundación Universitaria Bautista en Cali, Colombia. rocainar@hotmail.com
} 


\section{Introducción}

Uno de los aportes fundamentales de la memoria colectiva al estudio del NT tiene que ver con la relación entre la tradición oral y la escrita y su conformación. Para el análisis de esta relación, a partir de la memoria, se parte de la constatación de que en el proceso de formación del NT existe una cierta "ruptura de tradición" (Assmann, 2008) que es necesario "salvar" a partir de una posible relectura de los hechos fundantes del cristianismo, realizada por las primeras comunidades de los discípulos y de las discípulas de Jesús, dentro de ellas lo que podríamos reconocer como comunidades judeocristianas. En dicho proceso, estas comunidades van a confrontarse con otros grupos sociales y religiosos, con los cuales se va a tomar distancia, incluyendo el mismo judaísmo. La identidad del "nosotros" se contrapone a la de "ellos", los que no pertenecen a la comunidad. Así, en la memoria colectiva de las comunidades se intensifica esa búsqueda y recuperación del pasado para poder mantener una identidad propia con el paso del tiempo.

La perícopa de la mujer sorprendida en adulterio (PMA), por ser un texto tardíamente añadido al EJ, permite un ejercicio importante desde la perspectiva de la memoria, para entender mejor la relación entre la tradición oral y escrita que está detrás de la conformación del NT y de las primeras comunidades cristianas y judeocristianas. Esto va a requerir una búsqueda de la tradición detrás del texto y poder así evaluarla como parte de una tradición enraizada en las primeras comunidades judeocristianas y luego asumidas por las comunidades cristianas dentro de la tradición joánica. Es lo que se pretende mostrar en el presente artículo. La mujer sorprendida en adulterio, como sujeto, se muestra como un alterego de Jesús y de las comunidades judeocristianas. Se esta consciente que aquí sólo se dan algunas pinceladas y que de ellas se desprenden varios temas y desafíos para seguir profundizando y contribuir en una nueva mirada, la anamnética ${ }^{2}$, al estudio de los orígenes del cristianismo y sus implicaciones para hoy.

\section{Memoria colectiva y el estudio del Nuevo Testamento (NT)}

Hoy se plantea que frente a una perspectiva más bien repetitiva y pasiva de la memoria hay otra más "recolectiva", dinámica, que reconstruye el pasado en perspectiva de las necesidades e identidad de la comunidad que memoriza; un modelo más constructivista de la memoria. Lo que se concluye, en primer término, es que las tradiciones oral y escrita se mantienen simultáneamente en un proceso hacia una conformación más definitiva de la última; la primera no desaparece una vez surge la segunda. "En el mundo mediterráneo los escritos se entendían como la representación del discurso oral" (Aguirre, 2015b, p. 203). Al principio, hay una "continuidad" entre la tradición oral y la escrita, la cual supone la representación (performance) oral

\footnotetext{
${ }^{2}$ Anamnesis es el término en griego para memoria, por lo menos uno de los más usados.
} 
del texto, y que los textos escritos no se percibían como "copias exactas" de otro texto anterior y único, pues "no hubo aún un texto autoritativo de los evangelios" sino a fines del siglo cuarto ${ }^{3}$.

Igualmente hay un proceso constante de reinterpretación, una cierta discontinuidad, en donde fidelidad se une con creatividad en la tradición escrita, o quizás a través de ella. En general, la perspectiva clásica planteó una visión dualista entre memoria "auténtica", relacionada con el "Jesús histórico", y la tradición "fabricada" de las comunidades cristianas. En una perspectiva diferente, se revalora, en forma más favorable, el papel de la memoria de (sobre) Jesús dentro del "cascarón" de la tradición escrita trasmitida por las comunidades de los primeros siglos y que hoy se puede conocer.

Esta perspectiva, al reconsiderar el papel de la memoria colectiva, toma en cuenta la realidad social de las comunidades como un factor decisivo en la apropiación y construcción del pasado, y se aparta, del anterior acercamiento, al plantear que el cultivo de la memoria toma lugar dentro de una serie de ajustes propios de la "vida comunitaria" y un amplio rango de prácticas. Desde la memoria colectiva se traza que el ejercicio de conmemoración del pasado ejerce una poderosa influencia en la vida e identidad de la comunidad, que recuerda la comunidad anamnética. Entonces, "«Tradición» es así una abreviación para las incontables transacciones entre el pasado sacralizado y el presente vital actualizado de la vida de una comunidad" (Kirk y Thatcher, 2005, p. 33; traducción nuestra). Así, la cuestión no es intentar separar, sino entender su interconexión.

Las nacientes comunidades cristianas, sostuvieron una tensión entre la creatividad autoral, la "historia inventada", en un lado, y en el otro, entre la disciplina autoral, la "historia auténtica". En todo caso la memoria colectiva $^{4}$ es dinámica, un interminable flujo, creación imaginativa, variable abierta, aunque a veces también se cierra en una determinada tradición o línea. Complementando lo anterior, se plantea que...

...La memoria social descansa no tan solo en los eventos históricos sino en la narrativa que hace que éstos tengan significado para una comunidad. Hay un relato o narrativa anamnética. Pero hay que tener en cuenta que: "sin puntos de referencia históricos, podemos decir solamente que la memoria social varía, no podemos conocer cuánto y en qué dirección" (Schawartz, 2005 , p. 259 , traducción nuestra).

\footnotetext{
3 "El supuesto cierre del canon en el siglo cuarto, ni cambió su estatus ni aumentó su autoridad, era ya tan alto como podría ser. Con respecto a la función de estos libros, se podría decir con razón que ya existía un canon, o al menos la categoría de un canon, mucho antes del siglo IV... (sin embargo) Si el "cierre" del canon se refiere a un acto oficial de la Iglesia del Nuevo Testamento, entonces nos cuesta mucho encontrar tal acto antes el Concilio de Trento en el siglo XVI" (Kruger, 2012, p.37; traducción nuestra).

${ }^{4} \mathrm{~A}$ partir de los estudios de Halbwachs, quien a su vez parte de la sociología de Durkheim, se propone que la memoria es siempre una construcción social y por lo tanto colectiva. En 1925 publicó su primer libro sobre el tema: Los Marcos Sociales de la Memoria y en 1950 se publicó como obra póstuma un segundo libro, La Memoria Colectiva (Cf. Caicedo, 2019).
} 
En este sentido se realizará una discusión, primeramente, en el contexto de la obra del EJ y luego en la tradición que está detrás de la PMA, con relación a las comunidades judeocristianas ${ }^{5}$.

\section{La memoria de Jesús en el Evangelio de Juan (EJ)}

A diferencia de los sinópticos, “(El Evangelio de) Juan pinta a Jesús embarcado en largas discusiones que van y vienen, en varios escenarios. Sin embargo, hay dichos o partes de dichos que hacen eco al material sinóptico o forman diversas versiones de la tradición sinóptica" (Dunn, 2014, p. 95). Esta "dependencia" se explica mejor si el EJ conoció una tradición oral sobre Jesús, una similar a la empleada en los sinópticos, que sólo por la dependencia de una tradición escrita sinóptica. Esta tradición oral estaría relacionada con comunidades judeocristianas según se expone más adelante.

La tarea de la comunidad, guiada por el Espíritu (Jn 14,26; 16,12-13), para el EJ es la de "recordar (hypomnēsei, vi Jesús dijo y guiarlos a una más completa comprensión de la verdad" (Dunn, 2014, p. 99). En el EJ encontramos una visión más amplia de la memoria de Jesús de la que encontramos en los sinópticos, una visión más dinámica y compleja, así, “... Juan usa el mismo verbo griego (mnēmoneuō, $\mu v \eta \mu о v \varepsilon v \omega)$ para describir tanto la recolección hecha por los discípulos de los eventos ocurridos y la subsecuente interpretación de la Escritura para la clarificar su experiencia. (Thatcher, 2006, p. 27). En general, según Juan 2 y 12, la memoria de Jesús tuvo una importancia decisiva para la fe y la vida de las comunidades desde la primera generación de discípulos (as). En Juan 2,17 se dice que "se recordaron sus discípulos (sa) que lo que se había escrito es...". En el v. 22, "Cuando entonces fue levantado de los muertos, se recordaron sus discípulos que esto lo había dicho". Y en 12,16: "entonces se recordaron que estas cosas estaban sobre él escritas". En estos tres versículos vemos cómo la memoria se refiere tanto a las Escrituras hebreas como a las palabras de Jesús. Esta perspectiva del EJ es fundamental pues coloca el ejercicio de la memoria en una perspectiva amplia de un proceso en movimiento, en las comunidades de discípulos y de discípulas ${ }^{6}$.

Pero la peculiaridad de la perspectiva joánica, sobre la memoria de Jesús, es la apertura que plantea del proceso al mantener tan viva la tra-

\footnotetext{
5 "Judeocristianos se llaman, en el más amplio sentido, todos los cristianos de sangre judía. En cuanto denominación de un grupo concreto, este nombre es equívoco y ambiguo. Se dieron judeocristianismos que, gloriados de su ascendencia, formaron grupos especiales dentro de las comunidades de la gran Iglesia; $y$, finalmente, judeocristianismos -también llamados judaicos- que, al separarse paulatinamente de la mayoría, tuvieron un destino especial como grupo", considerados luego heréticos, (Schoeps, 1970, p. 11; resaltado nuestro).

6 "Aunque uno puede imaginar una similar funcional necesidad en los orígenes de los Evangelios (y sus hipotéticas fuentes literarias): textos escritos ayudaron a los primeros cristianos a recordar información tradicional acerca de Jesús, de este modo preservar su memoria contra las vicisitudes de la amnesia y la oralidad salvaguardando los datos que eran críticos a su existencia comunitaria en formación" (Thatcher, 2006, p.15; traducción nuestra).
} 
dición oral como la escrita, con el paso de los años, en las comunidades cristianas y judeocristianas del siglo I y posteriores, por lo menos hasta el siglo IV, cuando encontramos que se inserta la PMA (Cf. Caicedo, 2019, pp. 64-65). Para el EJ la memoria de Jesús es una compleja combinación de testimonio, recuerdo, fe y tradición. Después de la experiencia pascual y de su resurrección, los (as) discípulos (as) se recordaron lo que había dicho y creyeron tanto en sus palabras como en las Escrituras (Jn 2,22). Estos discípulos y estas discípulas dieron testimonio de dichas palabras y de la experiencia a las siguientes generaciones, y éstas a su vez testificaron a nuevas generaciones, con el fin de que creyeran en Jesús y su mensaje, como se le señala al final del EJ (Jn 21,24-25). Notemos el giro que encontramos en Juan 21,24: "Este es el discípulo que testifica sobre estas (cosas) y las que fueron escritas, y conocemos que su testimonio es verdad"; de la expresión en singular a la expresión en plural. Además, se resalta que hay dos pasos iniciales, el testimonio, de forma oral inicialmente, (Cf. Jn 3,11.32; 4,39; 15,27; $19,35)$ y luego la tradición escrita, ambas son parte de la memoria de las comunidades posteriores.

Esta perspectiva, desde la memoria, puede ayudar a entender cómo puede tardíamente entrar una perícopa, como PMA, a una tradición escrita, sin que eso "perturbe" el legado trasmitido por las comunidades creyentes anteriores, y sin que traicione la mirada propia del EJ sobre Jesús y su memoria. Memoria y relectura estarían estrechamente relacionadas en las comunidades en donde se recibe alguna de las tradiciones de las enseñanzas de Jesús. Estas relecturas pueden incluir elementos que vienen de otras tradiciones, orales o escritas, como es el caso de la PMA en el EJ y ya presente en otras tradiciones vinculadas a comunidades judeocristianas anteriores.

\section{La PMA desde la memoria de las comunidades judeocristianas}

La evidencia de una inserción tardía en el EJ pone en duda que la historia de Jesús ofreciendo absolución a la mujer sorprendida en adulterio (PMA) (Jn 7.53-8.11) fuera "una genuina parte del Evangelio desde el comienzo, la asociación de la historia con este evangelio debe reflejar una conciencia temprana del rol importante jugado por la mujer en lo contado por Juan" (Callahan, 2005, p. 175). En la mayor parte de los documentos o testigos, en que se encuentra la PMA, a partir del siglo IV, ésta se introduce después de Jn 7,52 como parte de un discurso más amplio conocido como el “Discurso de los Tabernáculos" (DT) (Jn. 7,1-8.59), pero no es el único lugar en donde se puede encontrar, también está en Lucas (Cf. Metzger, 2002, pp. 188-189). Para Rius-Camps (2008), la PMA pudo haberse encontrado inicialmente en el Evangelio de Marcos y de allí haber pasado al de Lucas, pero que debido a su "aparente lenidad en el campo de la moral" había sido suprimida de ambos evangelios, pero conservada por diversas tradi- 
ciones orales o escritas hasta que fue incorporada en el EJ, "de ahí la gran abundancia de variantes, 80 o más en 183 palabras, la mayor densidad de variantes que se da en todo el Nuevo Testamento" (p. 16).

Pero también la perícopa se encontraría en el Evangelio de los Hebreos (EH) (\# 102) (Hispano, 2003) 7 . El EH es retocado en el año 300, donde se incluyen elementos de otros apócrifos, y luego traducido al latín en el 400 por Jerónimo, ¿Pseudo-Jerónimo?, así lo atestiguó Papías (c. 125) citado en Eusebio de Cesárea ( 339) en Historia Eclesiástica III, 39,17. Forma parte de un grupo de textos que representan un judeocristianismo más radical que no se incorporó a la corriente principal de la "Gran Iglesia", así sucedió también con el Evangelio de Tomás de carácter menos narrativo que los otros. Esta tradición apócrifa nos muestra, en general, un Jesús como maestro o profeta de la "sabiduría de la vida en el presente", como parece mostrar también el DT en el EJ, que se asemeja a una "historia o relato de sabiduría" (Aguirre, 2015, p. 253).

Teniendo en mente esta discusión (Cf. Klauck, 2006), se podría plantear las siguientes posibilidades para que la PMA haya llegado hasta el EJ en el siglo IV:

- Era parte de un Proto-Mateo, aunque no se introduce en el Mateo canónico, pero se recoge en el EH y luego en la redacción posterior del EJ.

- Proviene de otra fuente diferente al Proto-Mateo, propia del EH y luego en la redacción posterior del EJ.

- Proviene de un contexto más helenizado a mediados del siglo II y recogida en la redacción posterior del EJ tanto como del EH.

Se puede entonces proponer, teniendo en cuenta lo anterior, que la perícopa sería parte de una tradición oral, luego insertado en la tradición escrita del EH y a la vez trasmitida en un texto escrito cercano a la tradición sinóptica, pero que no es incluida en la versión posterior de los evangelios canónicos. La PMA, luego, es conocida principalmente por teólogos alejandrinos, trasmitida y conocida en la tradición Occidental y Latina. Si es así,

\footnotetext{
${ }^{7}$ El Evangelio de los Hebreos es parte de los evangelios judeo-cristianos, junto con el Evangelio de los Nazarenos y el de los Ebionitas. Sin embargo, "Tenemos que asumir la existencia de una corriente más amplia de trasmisión, con tradiciones orales y un número de fuentes literarias mayor que dos o tres textos -o que una variedad de redacciones de esos dos o tres textos. Estos textos evangélicos se datan normalmente en la primera mitad del siglo II" (Klauck, 2006, p. 64). En su carta a Macario, Jerónimo plantea lo siguiente con respecto al EH: "La intención manifiesta de su autor ha sido recopilar en un solo volumen todos los dichos y todos los milagros de Jesús narrados por los Evangelistas... mi opinión actual es que debió ser compuesto privadamente por algún escriba cristiano de los que regresaron a Jerusalén tras el exilio a Pella... parece que el evangelio hebraico representa el último grado o fase en ese desarrollo (antes de la redacción completa de los Evangelios), pues con razón ha sido calificado de "completísimo" por Epifanio. Reúne otra vez todas las fuentes, como hizo S. Lucas, pero ya después de este Evangelio y de S. Juan, y las vuelve a poner en su lengua madre, para delicia de los que la hablaban" (Hispano, 2003, pp. 20-21).
} 
la PMA recoge la memoria de algunas comunidades cristianas tempranas, judeocristianas, que luego es asumida en una forma más amplia por comunidades propiamente cristianas e insertada en el texto joánico ${ }^{8}$. En este sentido, la ausencia de la PMA puede ser explicada por un "silencio" frente a la historia por parte de los copistas del EJ. (cf. SNAPP, 2014, p.12). La cuestión central sería: ¿Por qué fue importante para algunas de las comunidades judeocristianas retomar la historia de Jesús y la mujer adúltera? ¿Con qué imagen de Jesús resultaría familiar, dentro del contexto de comunidades judeocristianas? ${ }^{9}$

\section{La Narrativa de la PMA}

La narrativa de la PMA se ubica alrededor del conflicto entre Jesús y las autoridades judías. Jesús, que procede de Nazareth de Galilea, se mueve a Judea, donde se presenta principalmente el conflicto. Sin embargo, son algunos de los de Judea quienes dieron el testimonio sobre el cual la narrativa escrita del EJ depende, del círculo íntimo de Jesús. Principalmente "el (discípulo) amado de Jesús" $(13,23)$ y/o el "otro discípulo" $(20.2)^{10}$. Entonces esta tradición, de tipo sapiencial, compatible con una tradición temprana judeocristiana, ha llegado al EJ para mostrar a Jesús como "Sabiduría de Dios", desde el prólogo (1,1-18) con la mención del logos (Cf. Ringe, 1999 y Tragan y Perroni, 2017). Lo interesante es que la PMA se enmarque en esta narrativa, como una historia de sabiduría ${ }^{11}$, pues de alguna forma se constituye en una narración paralela a la de Jesús. Así como Jesús, la mujer es amenazada de ser apedreada (8:5) pero es rescatada por él de sus de-

\footnotetext{
8 "De este modo, se implican dos etapas dentro de la producción de la PMA: la primera etapa, en la que se produce la historia básica (y los elementos no joánicos son dominantes), y la segunda etapa, en la que la historia es revisada por un copista (mimic) (que deliberadamente agrega elementos joánicos) y se coloca dentro del texto del Evangelio de Juan. Uno podría preguntarse, ¿qué motivó esta mímesis (mimic)? Keith responde que "la mímesis era parte de una comunidad cristiana en la que la autoridad de Jesús fue desafiada con el argumento de que Jesús nunca escribió nada, y el objetivo de la mímesis era crear una versión del Evangelio de Juan que contuviera evidencia clara de que Jesús podía escribir" (SNAPP. 2014, p. 6; traducción y énfasis nuestros). 9 "En tal contexto (de EJ), si la perícopa hubiera aparecido repentinamente en escena, una reacción y protesta vigorosas parecerían casi inevitables. Aunque, vemos a obispos como Ambrosio y Agustín defendiendo la PMA. (Pero) en una época en la que las penitencias y penas por adulterio eran severas, esta historia en la que Jesús perdona a una adúltera - una adúltera que no ha expresado claramente su arrepentimiento- que se supone que apareció por primera vez en el texto de Juan alrededor del año 250 y que fue acogida dondequiera que circularon, sin una nota de protesta de nadie... (y) acepten de manera ligera y silenciosa la aparición repentina de una nueva historia en nuevas copias del Evangelio de Juan, donde tal historia no había existido previamente?" (SNAPP. 2014, p. 6; traducción nuestra).

${ }^{10}$ No necesariamente se trataría de dos discípulos diferentes sino mejor de estratos diferentes de la composición del Evangelio.

11 “Tomando en cuenta la innovación joánica, el relato de sabiduría es más apropiado como una descripción formal del discurso de los Tabernáculos, por dos razones. Primera, el discurso de los Tabernáculos emplea la tradición sapiencial y de sabiduría para conformar su retrato de Jesús como la Sabiduría de Dios... Segunda, el discurso de los Tabernáculos incorpora una línea de relato que corresponde con las características de un relato de sabiduría, de nuevo con ciertas innovaciones joánicas" (Cory, 1997, p. 103).
} 
tractores; igualmente, Jesús sale ileso de la confrontación, por el momento, pues también iba a ser apedreado por las autoridades judías, según el final del relato (8:59). El relato refleja entonces una situación de enjuiciamiento abierto, no dentro del contexto de una audiencia como tal, como característica de una historia de sabiduría.

La PMA muestra una confrontación de Jesús con sus principales detractores, en este sentido se presenta a Jesús como "Sabiduría de Dios"12 (hokmah, sophia), palabra (logos) y revelación de Dios $(1,1 ; 12,45 ; 14,9)$, una teodicea, presencia y gloria (Shekinah) $(1,14 ; 12,41)$, de allí que se pueda entender la acusación de "hacerse igual a Dios" $(5.18$; 10.33) que esgrimieron sus contradictores (Dunn, 2014, p. 107) y que se cristaliza en sus acciones. Pero si bien Jesús asume un rol de juez frente a sus acusadores, no lo hace con la mujer sorprendida en adulterio, al final del relato la expresión de Jesús es tremendamente reveladora e inesperada, "ni yo te condeno", como expresiones de juicio y defensa, de vida y muerte, de odio y perdón. El tema de la muerte aparece explícitamente siete veces en el contexto narrativo (Jn $7.1,19-20,25 ; 8.22,37,40)$.

La vindicación de Jesús como un maestro, o profeta de Sabiduría, es reforzada cuando se presenta una figura paralela a la de Jesús, que podríamos llamar un alterego, la mujer sorprendida en adulterio ${ }^{13}$. La mujer, al igual que Jesús, es juzgada por su acto en contra de la Ley, la moral de la familia y la comunidad es confrontada en juicio público; se busca que sea sentenciada al castigo que puede llevarla a la muerte para saldar su falta. La mujer es defendida por Jesús y Jesús es defendido por el Padre y su testimonio. La mujer es liberada del castigo y su culpa, Jesús será liberado por Dios después de pasar por la muerte, en la resurrección de su cuerpo. Los que buscaban sus condenas y castigo son descubiertos en sus intenciones y se muestran como injustos ante la opinión pública; se habían equivocado al juzgar injustamente tanto a la una como al otro. Así, entonces, el relato presentaría a sus lectores un relato paralelo a la historia misma de Jesús. Como alterego de Jesús su función es mostrar, en un performance, la situa-

\footnotetext{
${ }^{12}$ El término sophia $(\sigma o \phi \iota \alpha)$ no aparece en el EJ, pero hay una relación de esta tradición de la sophia con la incorporación de la expresión griega del logos en el EJ. Los paralelos se plantean en cuanto a que la Sabiduría existía, junto con Dios, desde un comienzo de la creación y forma parte activa de dicha creación (Prov. 3,19; 8.22-31; Sab. 9.4, 9; Eclo. 24.1-12). Ahora, esa Sabiduría se "hace carne" en medio de la humanidad, para reflejar la luz de Dios en medio de las tinieblas (Jn 1.5; Eclo 24.32; Sab 6.12; 7.10.26; 24.8). En este sentido, "La sabiduría es co-creadora con Dios y por ende cuidadora de su creación (v.4). Lo que el logos-Jesús trae es la vida en plenitud (Jn 10,10) y la

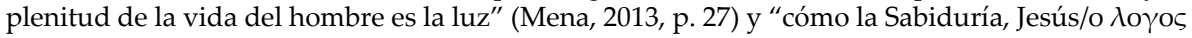
(ahora hecho carne) une al trabajo de Dios como creador con la pasión de Dios por una relación restaurada con la humanidad" (Ringe, 1999, p. 93).

${ }^{13}$ En el análisis narrativo se asemeja a un papel "figurante". "Al contrario que los protagonistas, los figurantes se limitan a servir de telón de fondo; pueden ser individuales o colectivos: una muchedumbre, un habitante, uno que pasa... Personaje simple que desempeña un papel pasivo o casi pasivo (telón de fondo) en el relato" (Marguerat, 2000, pp. 98-99). Un alterego representa al protagonista en su destino; en alguna forma "toma su lugar" y representa un desafío para él.
} 
ción misma de Jesús. La mujer se convierte en símbolo ${ }^{14}$ de Jesús; representa al Maestro perseguido y acusado de ser hereje. Como símbolo evoca ${ }^{15}$ un pasado común, tanto para las comunidades judeocristianas como para la comunidad que lee al EJ. Una de las funciones del símbolo es anamnética, hacer memoria, recuperar y promover la memoria colectiva como parte de una identidad grupal y comunitaria. El adulterio cometido en el ámbito de la vida de pareja, en la tradición judía, simboliza una acción en el ámbito religioso al hacer referencia a la idolatría y la blasfemia (Cf. Lev 24,14 (NVI); Ex 19,13; Lev 20,27; Lc 20,6; Hch 7,58; Deut 13.95; 21.23. Cf. Bruce, Marshal, Millard, Parker y Wiseman, 2003, p. 78).

Pero también la mujer es un alterego de la comunidad. El relato que sigue a la PMA en el EJ es la sanidad de un ciego de nacimiento (cap. 9). En este relato ha llamado la atención el término que designa el temor de los padres del ciego de ser expulsados de la Sinagoga $(9,22)$, aposynagōgos genētai ( $\dot{\alpha} \pi 0 \sigma v v \alpha \dot{\alpha} \omega \omega \gamma \sigma \varsigma \gamma \hat{\varepsilon} v \eta \tau \alpha \iota)$, expresión usada por el EJ en varias oportunidades $(9,22,12,42,16.2)$. "El uso de Juan de aposunagōgos es único; éste no se encuentra en ninguna fuente cristiana o Rabínica" (Sudermann, 1994, p. 45) y ha generado una serie de discusiones acerca de su constatación histórica. Podemos relacionar esta situación con un contexto propio de comunidades judeocristianas (Cf. Sudermann, 1994, pp. 45-48). La mujer sorprendida en adulterio sería un alterego de las comunidades en el contexto en donde ya se generaliza la acusación, las amenazas y en algunos casos la persecución de parte de las autoridades y comunidades judías.

...Las críticas y la polémica se recrudecerán entre los siglos III y IV. Estas polémicas contribuyeron a la desaparición del cristianismo judío, lo que agrandó aún más la brecha entre el judaísmo y el cristianismo. Por su parte, la tradición rabínica, que era bastante crítica con Jesús y el cristianismo, se impuso configurando el cristianismo posterior. (Álvarez, 2015, p. 385).

Así,

...la historia de transmisión de la perícopa adulterae puede apuntar a una naturalización de la retórica antijudía de tal manera que las acusaciones de acciones contra "los judíos“, independientemente de cómo se apliquen, podrían influir en la exégesis de los evangelios y la exégesis patrística independientemente de las tradiciones interpretativas compartidas. (Wright, 2006, p. 493).

\footnotetext{
14 “El símbolo no es solamente un signo o una realidad sensible que nos remite a una experiencia vital o a otra realidad distinta; es una tercera, la significación o el sentido que permite que el signo remita a una realidad o experiencia diferente" (Reyes, 1997, p. 45; resaltado nuestro).

${ }^{15}$ “El símbolo tiene la fuerza educativa de e-vocar, con-vocar y pro-vocar: El símbolo e-voca. Esta función del símbolo consiste en la capacidad de hacer presente (evocar), recordar o reconstruir mediante la memoria, explícita o implícitamente, personal o colectiva, la tradición cultural o religiosa de un determinado grupo... Al evocar, el símbolo interpreta, recrea y actualiza la tradición (relectura), generando un proceso indefinido de interpretaciones sucesivas" (Reyes, 1997, p. 89).
} 
Sin embargo, hay que reconocer que la PMA muestra a Jesús replanteando la Ley Mosaica frente a una posible interpretación judía más literal de la misma, sin preguntar: ¿A quién se juzga? ¿Por qué se juzga? ¿Es ese juicio verdadero, justo, equilibrado? ¿A quién favorece? Son preguntas que no se harían quienes traen a la mujer delante de Jesús, ni quienes llevan a Jesús delante de Pilatos. La confrontación de Jesús a ese uso "deshumanizante" de la ley de Moisés le coloca en oposición, al parecer, de las principales autoridades judías en su momento, como después pone a las comunidades judeocristianas frente al judaísmo ortodoxo.

\section{Las comunidades judeocristianas en el contexto del cristianismo de los primeros siglos}

Las comunidades judeocristianas, como los Ebionitas y Nazarenos, forman parte de una primera generación y juegan un papel determinante en la memoria de Jesús. Después del año 70, se van constituyendo en grupos judíos marginales que toman distancia tanto del judaísmo rabínico mayoritario como de las comunidades cristianas, principalmente de influencia paulina, ubicadas en la diáspora. Dentro de estos grupos se identifican los Ebionitas, Elcasaítas y Nazarenos. Se ubicaron principalmente en Siria $^{16}$ (EvMt, Santiago, Didajé, Odas de Salomón), Asia Menor (Apocalipsis, Montanismo), Egipto (Evangelios y Carta de Bernabé) y en Roma (Carta de Clemente a los Corintios y el Pastor de Hermas) (Aguirre, 2015, pp. 450452). El evangelio de los Hebreos, en el cual encontramos antecedentes de la PMA, se puede relacionar principalmente con la comunidad llamada de los Nazarenos que vivían en Berea (Alepo), Siria, según Jerónimo (De viris 3), y con los Ebionitas. Estos son descendientes de grupos que se refugiaron en Pella, ribera oriental del río Jordán, después del 70, y que posiblemente usaron un texto Mateano en hebreo o arameo (Santos, 1999, p.30) ${ }^{17}$. Los textos judeocristianos, como también el evangelio de Tomás, de carácter menos narrativo, nos pueden estar mostrando un Jesús como maestro de la "sabiduría de la vida", así como la PMA se presenta como una "historia o relato de sabiduría" (Aguirre, 2015, p. 253).

Posiblemente en las comunidades judeocristianas, que seguían contemplando la Ley mosaica con criterio ético-sagrado, la propuesta de Jesús

\footnotetext{
${ }^{16}$ En la zona de la Siria Oriental predominó el mundo rural, se hablaba el arameo o siriaco, su centro principal estaba en Edesa, al norte de Mesopotamia. Allí surge un cristianismo aramaico-judío, alrededor de la figura del apóstol Tomás y la ciudad de Edesa, pero que se diferencia de un judeo-cristianismo heterodoxo que profesan una cristología cercana a la joánica. Movimientos gnósticos de expresión griega, redacción final del EvTomás y María Magdalena.

${ }_{17}$ Por eso algunos plantearon que el EH es una ampliación de un proto-Mateo, así Epifanio ( $\mathrm{T}$ 403). Jerónimo lo traduce al griego y latín y lo considera mucho más que otros textos apócrifos en sus comentarios seguramente por su conexión con el proto-Mateo. "Los pocos fragmentos que nos han llegado provienen casi únicamente de las citas de Jerónimo" (PENNA, 2012, p.406). El EH y Ev. Ebionitas parecen representar un judeocristianismo radical, que no se incorporó a la corriente principal de la "gran Iglesia".
} 
llega a ser normativa y pasa a ser criterio interpretativo de la Ley. El sujeto, sobre todo, excluido, marginalizado y victimizado, pasa a ser criterio hermenéutico de la Ley y de la tradición judía. En ese sentido que Jesús haya "escrito" algo, aunque lo haya hecho en la tierra, resuena en sus oídos como una forma de justificar dicha tarea. Ese gesto de Jesús adquiere un valor simbólico en el contexto del conflicto con las autoridades judías, pues escribir es una acción de autoridad, no cualquiera escribe, no tan sólo porque no pueda sino porque no debe hacerlo. El gesto puede evocar la situación en que Daniel es llamado para descifrar lo que Dios escribe en la pared del palacio del rey Belsasar (Dn 5,1ss), donde el juicio de Dios se revela al monarca "enviando una mano que escribe" (Dn 5,24. LXT) y que luego el Profeta interpreta. Así, "desde la perspectiva de la intención del autor, este fenómeno puede ser etiquetado como la función simbólica o retórica de la escritura, la producción de documentos en culturas donde la palabra escrita tiene especial peso o autoridad" (Thatcher, 2006, p. 37). Tal peso o autoridad sería más entendible en el contexto de los siglos posteriores al siglo I, donde la tradición escrita dentro del cristianismo apenas comienza y va ganando un espacio de credibilidad.

Así, el "evangelio" de Jesús se presenta como una nueva forma de interpretar la ley desde la perspectiva de valorar la vida del sujeto y no de su muerte. Es el evangelio que ahora se escribe en la tierra, en el corazón del ser humano, y no en tablas. El ser humano es tierra, donde escribe Jesús su evangelio y luego la comunidad por su predicación. En esta perspectiva lo plantea Jerónimo (1962): "Porque si la ley, dada por mano de mediador, fue escrita por el dedo de Dios (digito Dei), y lo que estaba llamado a la desaparición fue glorioso, cuánto más ha de escribirse por el Espíritu Santo, valiéndose de mi lengua, el Evangelio, destinado a permanecer" (p. 595).

\section{A manera de conclusión}

En este artículo se ha planteado la importancia, cada vez más creciente, de los aportes de los estudios de la memoria para una interpretación de los textos bíblicos como parte de un proceso colectivo ligado a la construcción de memoria en las comunidades creyentes. En el contexto de la formación del NT estas las diversas tradiciones, escritas y orales, se superponen y se complementan; es más, la tradición escrita debe abrirse paso en una sociedad en donde la oral tiene una relevancia que hoy ya no tienen, en nuestras sociedades. La memoria juega un papel constitutivo en ambas y a la vez un papel mediador entre ambas.

Desde la perspectiva de la memoria social los textos narrativos, como es el caso de la PMA, pueden mostrar elementos más inestables, cambiantes, que otros en su trasmisión. En el recorrido que se ha hecho en el análisis de la historia de la mujer acusada de adulterio, y este giro es intencional, podemos notar algunos de estos elementos si tenemos en cuenta una versión, 
o varias, anterior de la narración en el EJ. En todo caso, el texto nos muestra a un Jesús que busca superar los odios y la violencia simbólica que se ejerce frente a la mujer por parte de las autoridades religiosas.

¿Qué podemos resaltar de la discusión anterior para nuestros días? Más allá de la discusión de si el texto se trasmite tal cual desde la vida de Jesús, cosa que se ve muy probable si tenemos en cuenta su trasmisión en el contexto de algunos grupos judeocristianos, nos lleva a considerar principalmente la crítica, asumida por las comunidades creyentes, judeocristianas y cristianas, frente a las autoridades religiosas judías y su interpretación de la Ley Judía. Esta crítica, reconocida como propia de Jesús por las comunidades, frente a los líderes religiosos judíos tiene que ver con lo que hoy se puede llamar una violencia simbólica, es decir, una violencia que, a diferencia de la violencia física, cuesta a veces percibir y cuestionar, pues se naturaliza a partir de las relaciones sociales reconocidas en un contexto determinado (Cf. Bourdieu, 2000, pp. 11-12).

Es pues el desconocimiento del sujeto lo que prima en el relato de la PMA, y lo que ha primado en la historia de nuestras sociedades, el desconocimiento de los otros u otras diferentes al nosotros. Dentro de los caminos de dicha violencia simbólica tenemos el elaborado a partir de la religión. En el caso de la PMA este camino se expresa a partir de la interpretación y ejercicio de la ley Mosaica, hoy se expresa a partir de interpretaciones del texto bíblico desde posturas excluyentes de la mujer ${ }^{18}$, para las cuales, tal ejercicio, se puede convertir en algo natural y aceptado. La PMA nos muestra cómo funciona una sociedad patriarcal y, también, cómo Jesús, se sale de su esquema y lógica proponiendo así una alternativa a la violencia simbólica que opera en ella. La relectura de los textos bíblicos a partir de categorías sociológicas nos permite entenderlos como parte de una dinámica social y cultural propia, al leerlos hoy, debemos captar su potencialidad y el aporte que hacen para nuestra sociedad en donde encontramos puntos comunes con esa condición del texto, aunque guardando las diferencias. Nos queda el desafío, de entender cómo una perícopa como la PMA, habla a una sociedad en donde no se supera el patriarcalismo y la violencia, simbólica y material, en contra de las mujeres y otros sectores marginalizados. Tristemente, se puede ver cómo sigue en aumento la violencia contra la mujer en el contexto de los hogares y la sociedad en general Da tristeza pensar que los hogares no sean los sitios más seguros y libres de cualquier forma de violencia contra la mujer, así como contra los niños y las niñas (Cf. Observatorio, 2020). Entristece, también, una sociedad indolente y permisiva frente a dicha violencia, donde las leyes y autoridades se hacen pesadas y

\footnotetext{
${ }^{18} \mathrm{Al}$ igual que otras ideologías dominantes, tales como el racismo y el colonialismo, la sociedad patriarcal ejercería un control insuficiente, e incluso ineficaz, de no contar con el apoyo de la fuerza, que no solo constituye una medida de emergencia, sino un instrumento de intimidación constante" (Millett, 1975, p. 58).
} 
lentas para frenar los casos de feminicidios que siguen siendo cada vez más frecuentes. (Cf. Rodríguez, 2017, p. 56).

\section{Bibliografía}

AGUIRRE, R. (2015). La Memoria de Jesús y los Cristianismos de los orígenes. Estella: Verbo Divino.

AGUIRRE, R. (2015b). La segunda generación y la conservación de la memoria de Jesús: el surgimiento de los evangelios. En R. A. (ed), Así empezó el cristianismo (págs. 195-254). Navarra: Verbo Divino.

ALAVAREZ, D. (2015). El Cristianismo en el Imperio Romano (sigos I-II). En R. A. (ed.), Así empezó el cristianismo (págs. 379-426). Navarra: Verbo Divino.

ASSMANN, J. (2008). Religión y Memoria Cultural: Diez estudios. Buenos Aires: Limod.

BERNABÉ, C. (2015). Las comunidades joánicas: un largo recorrido en dos generaciones. En R. A. (ed.), Así empezó el cristianismo (págs. 293-340). Navarra: Verbo Divino.

BOURDIEU, P. (2000). La dominación masculina. Barcelona: Anagrama.

BRUCE, F., MARSHAL, I., MILLARD, A., PARKER, J., \& WISEMAN, D. (2003). Nuevo Diccionario Certeza. Barcelona: Certeza Unida.

CAICEDO, R. (2019). Evanegelio de Juan y el papel de la Memoria Social. Kronos, 35-76.

CALLAHAN, A. D. (2005). The Gospel of John as people's history. En R. H. (ed.), Christian origins (págs. 162-176). Minneapolis: Fortress.

CESAREA, E. de (s.f.). Historia Ecelsiástica, libro III. Bibliotheca Patrística.

CINNIRELA, M. (1998). Exploring temporal aspects of social identity: the concept of possible social indentities. European Journal of Social Psychology, 28, 227-248.

CORY, C. (1997). Wisdom"s rescue: A new reading of the Tabernacles discourse (John 7:1-8:59). Journal of Biblical Literature, 95-116.

De WIT, H. (2010). En la dispersión el Texto es Patria. San José: UBL.

DUNN, J. (2003). Jesus remembered. Grand Rapids: Eerdmans pub. comp.

DUNN, J. (2014). Del Evangelio a los Evangelios. Bogotá: San Pablo.

DUNN, J. (2014). Del Evangelio a los Evangelios. Bogotá: San Pablo.

ESTÉVEZ LÓPEZ, E. (2015). Las mujeres en los orígenes cristianos. En R. A. (ed.), Así empezó el cristianismo (págs. 481-548). Estella: Verbo Divino.

GUIJARRO, S. (2008). Memoria Cultural e identidad de grupo en el Documento Q. En C. G. Carmen Bernabé, Reimaginando los orígenes del Cristianismo (págs. 193-218). Estella: Verbo Divino.

HALBWACHS, M. (1992). On Collective Memory. Chicago: University of Chicago Press.

HALBWACHS, M. (2004). Los Marcos sociales de la Memoria. Barcelona: Anthropos. 
HEARON, H. (2005). The Story of "the woman who anointed Jesus" as social memory: A methodological proposal for study of tradition as memory. En A. K. (eds), Memory, tradition and text (págs. 99-118). Atlanta: SBL.

HISPANO, P. L. (2003). Evangelio de los Hebreos. Texto supuesto de un apócrifo perdido. Madrid: EDIBESA.

JERÓNIMO. (1962). Cartas de San Jerónimo (Bilingue ed., Vol. I). (D. R. Bueno, Trad.) Madrid: BAC.

KELBER, W. (1983). The Oral and the Written Gospel. Filadelfia: Fortress.

KELBER, W. (2002). Teh case of the Gospels: Memory's Desire and the limits of Historical Criticism. Oral Tradition, 17/1, 55-86.

KELBER, W. (2005). The works of memory: Christian Origins as MnemoHistory-A response. En T. T. Alan Kirk, Memory, Traditions and Text (Vol. Semeia Studies 52). SBL.

KELBER, W. (2006). The Generative Force of Memory: Early Christian Traditions as Processes of Remembering. Biblical Theology Bulletin: A Journal of Bible and Theology, 15.22.

KIRK y THATCHER. (2005). Memory, Tradition and Text: Uses of past in Early Christian (Vol. 52). Semeia Studies.

KLAUCK, H.-J. (2006). Los evangelios apócrifos, una introducción. Santander: Sal Terrae.

KRUGER, M. J. (2012). Canon Revisited: Establishing the Origins and Authority of the New Testament Book. Wheaton: Crossway.

MARGUERAT, D. (2000). Cómo leer los relatos bíblicos. Iniciación al análisis narrativo. Santander: Sal Terrae.

Mena, M. (2013). Palabra-Sabidurìa sìmbolo del nuevo tiempo en Juan. En J. Bautista, M. Mena, M. B. Rodrìguez, \& F. Torres, Perspectivas de inclusion en el Evangelio de Juan (págs. 16-38). Bogotà: KairEd.

METZGER, B. M. (2002). A textual Commentary On The Greek New Testament (4 revisada ed.). New York: United Bible Societies .

METZGER, B. M. (2002). A Textual Commentary On The Greek New Testament (4a. Revisada ed.). New York: UNITED BIBLE SOCIETIES.

MILLETT, K. (1975). Política sexual. México, D.C.: Aguliar.

OBSERVATORIO Feminicidios Colombia. (julio de 2020). Boletín Nacional.Colombia.Vivas nos queremos. Obtenido de obervatoriofeminicidioscolombia.org: http://observatoriofeminicidioscolombia.org/ attachments/article/436/Bolet\%C3\%ADn\%20Vivas\%20Nos $\% 20$ Queremos\%20Julio\%202020.pdf

PENNA, R. (2012). La Formación del Nuevo Testamento en sus tres dimensiones. Estella: Verbo Divino.

PEÑA, R. (1999). Introducción y notas. Biblioteca de Patrística. Jerónimo, Comentario al evangelio de Mateo. Madrid: Ciudad Nueva.

PSEUDO LEVÍ. (2003). El Evangelio de los Hebreos. 
REYES, F. (1997). Hagamos Vida la Palabra. Método de Lectura Bíblica. Bogotá: CEDEBI.

RINGE, S. H. (1999). Wisdom's friends. Louisville: Westminster John Knox Press.

RIUS-CAMPS, J. (2008). El Evangelio de Marcos: etapas de su redacción. Estella (Navarra): Verbo Divino.

RIVAS, F. (2015). El nacimiento de la Gran Iglesia. En R. A. (ed.), Así empezó el cristianismo (págs. 427-480). Estella (Navarra): Verbo Divino.

RODRIGUEZ, L. (2017). Bajo el signo de la caída. la violencia contra las mujeres en la Biblia y sus efectos en el imaginario social. En A. B. (ed.), Caín, ¿Dónde está tu hermana?, Dios y la violencia contra las mujeres (págs. 47-85). Navarra: Verbo Divino.

Rodríguez, Y. (2010). El Alba: la integración Subalterna desde América Latina, una mirada Gramsciana de la Relaciones Internacionales. En M. H. (comps), Librémonos de la Guerra. Segundo seminario internacional Antonio Gramsci 20. Bogotá: UNIJUS.

SANCHEZ, W. G. (09 de Mayo de 2018). Jesús y la mujer adúltera, análisis exegético-teológico de Juan 7.53-8,11. Obtenido de https://es.scribd. com/: https://es.scribd.com/document/378699799/Jesus-y-La-MujerAdultera-pdf

SANTOS, A. D. (1999). Los Evangelios Apócrifos. Madrid: Biblioteca de Autores Cristianos.

SCHOEPS, H.-J. (1970). El Judeocristianismo. Alcoy (España): Marfil.

SCHWARTZ, B. (2005). Jesus in first-century Memory- A response. En T. T. Alan Kirk, Memory, Tradition and Text (págs. 249-261). Atlanta: SBL.

SNAPP, J. (2014). The 2014 Pericope Adulterae. Symposium at SEBTS (págs. 1-15). Wake Forest: SEBTS. Obtenido de http://www.thetextofthegospels.com/2014/05/the-2014-pericope-adulterae-symposium_7.html

SUDERMANN, R. (5 de mayo de 1994). The replacement pattern in the Fourth Gospel: A persecuted community confronts its past. Tesis. Boogtá: Pontificia Universiad Javeriana.

THATCHER, T. (2006). Why John Wrote a Gospel. Jesus-Memory-History. Louisville: Westminster John Knox Press.

TRAGAN, P.-R., \& PERRONI, M. (2017). Nadie ha visto jamas a Dios. Navarra: Verbo Divino.

De WIT, H. (2008). “Camino de un día” (Jonás 3,4) Jonás y la Memoria Social de los pequeños. Theological Xaveriana, 58(165), 87-126.

WRIGHT KNUST, J. (2006). Early Christian Re-Writing and the History of the Pericope Adulterae. Journal of Early Christian Studies, 14(4), 485536.

Roberto Caicedo 